\title{
Lessons Learnt From the Applications of QFD to the Definition of Complex Systems
}

\author{
Dr. Amihud Hari \\ System Engineering and \\ Evaluation Center (SEEC), \\ UNISA, Mawson Lakes SA \\ 5095, Australia \\ Email: amihud.hari@unisa.edu.au
}

\author{
Prof. Joseph E. Kasser \\ Systems Engineering and \\ Evaluation Centre (SEEC), \\ UNISA, Mawson Lakes SA \\ 5095, Australia \\ Email:Joseph.kasser@unisa.edu.au
}

\author{
Prof. Menachem P. Weiss \\ Faculty of Mechanical \\ Engineering, \\ Technion, Haifa, 32000, \\ Israel \\ Email: mweiss@technion.ac.il
}

Key words: New-Product Definition (NPD), Customers Needs, Requirements, Performance Based Specification (PBS), Quality Function Deployment (QFD), Case Study, Lessons learned.

\begin{abstract}
Quality Function Deployment (QFD) has been used to elucidate and negotiate requirements for at least 20 years. QFD has a lot to offer but when used to specify complex systems, has been found to have a number of deficiencies, has been perceived as a time consuming process and has been found as being difficult to apply to complex systems. This paper summarizes the top five lessons learned from 15 years of experience in using QFD in the elicitation, elucidation and negotiation of requirements for complex systems.
\end{abstract}

\section{Introduction}

The House of Quality is the matrix tool used in QFD to translate customer's needs into product characteristics. Product characteristics also known as Measures of Performance are attributes expressed in technical terms as the (Voice of Engineering (VOE)) which are used to measure the performance of the product. Examples are range, accuracy, weight, reliability, cost, or time to market. However, when used to specify complex systems, QFD has been found to have a number of deficiencies, has been perceived as a time consuming process and has been found as being difficult to apply to complex systems. This paper summarizes the top five lessons learned from 15 years of experience in using QFD in the elicitation, elucidation and negotiation of requirements for complex systems. In order of importance, contribution and novelty, these top five lessons learned are:

- QFD does not support making target value decision tradeoffs for complex systems.

- QFD is only a part of the process that produces the definition of a complex system.

- The methodology for definition of a complex system must be tailored to the unique characteristics of each product, organization and culture.

- QFD cannot be used when requirements are stated in Tender documents.

- QFD is a time consuming process and difficult to apply for complex systems.

However, to facilitate following the paper, these lessons learnt are discussed in the following order to help people not familiar with QFD to follow the flow of the paper.

- QFD is a time consuming process and difficult to apply for complex systems.

- QFD is only a part of the process that produces the definition of a complex system.

- QFD does not support making target value decision tradeoffs for complex systems.

- The methodology for definition of a complex system must be tailored to the unique characteristics of each product, organization and culture.

\footnotetext{
${ }^{1}$ Copyright $@ 2006$ by Amihud Hari, Joseph Kasser and Menachem Weiss. Published and used by INCOSE with permission.
} 
- QFD cannot be used when requirements are stated in Tender documents.

\section{Lesson Learnt: QFD is a Time Consuming Process and Difficult to Apply for Complex Systems}

One of the problems when using QFD with complex system products and multi-level hierarchical systems consisting of subsystems, assemblies, subassemblies and many parts, is difficult to deal with the many needs of customers and the large number of characteristics (Hari and Zonnenshain, 1993). These problems are caused by the time-consuming nature of QFD. A matrix of more than $20 \times 20$ or $15 \times 25$ is impractical to handle because it consumes too much time. This makes it difficult for the team to analyze all customers' needs in depth and formulate all correlations and tradeoffs.

\section{Remedy: Modified House of Quality}

The remedy for this situation is to modify the House of Quality to only use:

- 15-20 system level needs (rows), and if necessary also trim the customer needs hierarchy tree.

- $20-25$ product characteristics (columns), these being the most important, difficult, or controversial decisions. These are selected in the preparation process for the QFD workshop by the representatives of both the VOC and the VOE. In addition, the House of Quality was modified by adding a column entitled "Other characteristics". This column is a placeholder for the team to note any product characteristic which contributes to satisfying a need and is not already included in the 20-25 characteristics for discussion.

A typical modified House of Quality is shown in Figure 1. The multi-functional team fills in the relationship between the VOC and the characteristics. They analyse how much each characteristic contributes to each customer need. The team seeks consensus on these evaluations. The team use symbols to present the strength of the relationships as shown in Table 1.

The QFD literature (Cohen, 1995; King, 1989) suggests that time be spent quantifying the competitor's ratings and discussing selling points. In the modified QFD only the name of the competitor who is perceived as being the best in the market in satisfying this need is noted. However, it also seemed worthwhile to present technical information about the competitor's product and the reason for

Table 1 Representation of relationships

\begin{tabular}{|c|l|l|}
\hline Symbol & \multicolumn{1}{|c|}{ Contribution. } & $\begin{array}{c}\text { Recommended } \\
\text { value }\end{array}$ \\
\hline$\bullet$ & Strong & 9 \\
\hline $\mathbf{O}$ & Moderate & 3 \\
\hline$\Delta$ & Weak or indirect & 1 \\
\hline
\end{tabular}
it's perception by the customers as being the best in the market.

The analysis of the correlations among the product characteristics in the roof of the House of Quality is time consuming, and provides little benefit. Instead it was decided to discuss only correlations that actually affect the decision on target values.

The formal output of the modified House of Quality is the ranking of the important product characteristics by relative importance (but all of them are important otherwise they would not be discussed in this stage). But the greatest benefit of the process of populating the modified House of Quality is the communication and detailed discussion between all the disciplines that are represented in the team and especially between the VOC and the VOE. 


\begin{tabular}{|c|c|c|c|c|c|c|c|c|c|c|c|c|c|}
\hline $\begin{array}{l}\text { Project: } \\
\text { Flashlight for the Elderly }\end{array}$ & \multicolumn{5}{|c|}{$\begin{array}{l}\text { Company: } \\
\text { Light Light }\end{array}$} & & & & & & & \multicolumn{2}{|c|}{$\begin{array}{l}\text { Workshop Date: } \\
\text { 1.1.02 }\end{array}$} \\
\hline \multicolumn{14}{|c|}{ House of Quality } \\
\hline & & Pro & $\mathrm{du}$ & ct's & C & ar & icte & ris & & & & & \\
\hline & A & C & & E & 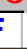 & & 11 & & & $\mathbf{M}$ & & & \\
\hline Customers' Needs & 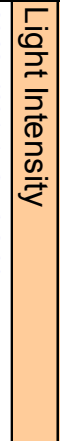 & 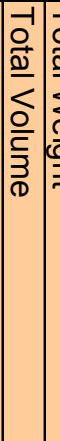 & & : & & & 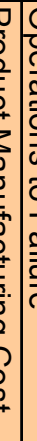 & & 0 & & 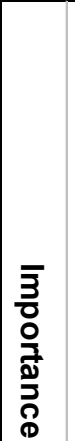 & 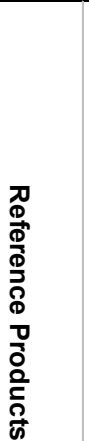 & Other Characteristics \\
\hline $\begin{array}{l}\text { Scenario No. 1: Find light switch } \\
\text { or door lock in dark }\end{array}$ & $\Delta$ & $\mathrm{O}$ & 0) & O & & & 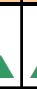 & & & & 10 & Now & Light Focus \\
\hline $\begin{array}{l}\text { Scenario No. 2: Primary } \\
\text { orientation at home while } \\
\text { electrical blackout }\end{array}$ & 0 & $\mathrm{O}$ & $\Delta$ & 은 & & D & 1 & c & & & 9 & Now & \\
\hline $\begin{array}{l}\text { Scenario No.3: Find my way in } \\
\text { dark streets }\end{array}$ & - & O & o) & o & & D & (c & & & & 5 & Now & \begin{tabular}{|l|} 
Environmental \\
conditions: Spalsh \\
resistance \\
\end{tabular} \\
\hline $\begin{array}{l}\text { Easy to carry in pocket or } \\
\text { handbag }\end{array}$ & $\Delta$ & - & - 1 & O & & & | & 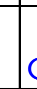 & & & 24 & $\mathrm{X}$ & \\
\hline $\begin{array}{l}\text { Easy to find and to operate in } \\
\text { dark }\end{array}$ & 0 & $\bullet$ & - & - & - & & 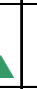 & c & & & 8 & Now & \\
\hline $\begin{array}{l}\text { The logistic scenario: Easy to } \\
6 \text { maintain (or no maintenance) } \\
\end{array}$ & & & & & D & & t & 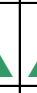 & & & 3 & $\mathrm{Y}$ & MTTR: User Level \\
\hline $\begin{array}{l}\text { Operates reliably when needed } \\
\text { and does not operate when not } \\
\text { needed }\end{array}$ & & $\mathrm{O}$ & 의 & & ב & & ? & 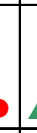 & & & 20 & $\mathrm{Y}$ & \\
\hline Affordable & $\Delta$ & & & $\Delta$ & $\Delta$ & D & (c) & 2 & & & 13 & $\mathrm{x}$ & \\
\hline Looks nice, smooth touch & $\Delta$ & & & o & & & 5 & ( & & & 8 & $\mathrm{Y}$ & \\
\hline 10[ & & & & & & & & & & & & & \\
\hline Total importance & $\vec{E}$ & $\frac{ \pm}{6}$ & 龺 & 0 & $\omega$ & & ¿ & 4 & & & 2579 & & \\
\hline Relative importance & : & $\vec{a}$ & $\stackrel{\vec{a}}{\circ}$ & 0 & s) & & & & & & $\vec{b}$ & & \\
\hline Rank & $\infty$ & -1 & 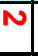 & + & ( & 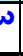 & 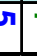 & & & & & & \\
\hline
\end{tabular}

Figure 1 House of Quality for the flashlight case study

\section{Lesson Learnt: QFD is only a part of the process that produces the definition of a complex system}

QFD cannot on its own produce the definition or system specification. Other activities such as the determination of the voice of the customer (VOC), and of the remaining requirements, the production of a complete specification document and a Stage Gate Requirements Review are essential parts of a complete process for new-product definition.

\section{Remedy: Develop and use New Product Definition Process (NPD)}

The remedy for this lack of a complete process is to have one and NPD was developed based on the experience that produced these lessons learned. NPD is a customer-driven, systematic, expeditious, and cost-effective Meta-methodology for defining the performance requirements for new products. It is called a Meta-methodology since the activities that must be performed to produce a complete set of requirements for a new product can be 
implemented by various methodologies. NPD serves to identify, jointly with customers or their representatives, the target-values of the most critical product characteristics which will meet the real needs of the customer at the best value.

The NPD Meta-methodology bounds the necessary activities in the following five steps described below:

1. Determination of the VOC.

2. Determination of the remaining requirements (requests).

3. Creation of the New Product Definition

4. Production of a complete draft Performance Based Specification (PBS).

5. A Stage Gate Requirements Review resulting in the approval to proceed with the design of a product that will comply with the signed-off PBS.

Steps 1 and 2 may be performed in parallel, Steps $1-4$ are sometimes performed in an iterative manner in the case of complicated products. Step 5 is the final step of the methodology. Each step may use different methodologies, processes and tools, as described herein depending on the situation, hence the recommendation for using a Process Architect (Kasser, 2005) to design the appropriate process for a specific situation. Consider each of the steps in turn.

Step 1: Determination of the voice of the customer: The objectives of Step 1 are:

- to identify the customers and stakeholders;

- to ensure that the definition of the characteristics of the new product is driven by, and focused on, the real needs of the customers and users;

- to identify the hidden needs as well as the known needs;

- to create a baseline to justify the product specification;

- to verify that no critical need is omitted;

- to ensure the product development team understand the real needs;

- to develop a common language within the product development team to describe the needs, and

- to prioritize the needs.

- to produce a documented VOC.

In systems engineering, Step 1 tends to be known as the requirements elicitation and elucidation process. In this step the stakeholders and customers are identified and their real needs are determined. Step 1 takes place within the context of a high degree of communication with the desired customer coupled with knowledge of the user's needs. It is best performed by an Integrated Product Development Team (IPDT) which analyses and captures the needs. The membership of the IPDT comprises staff from design, manufacturing, logistics, and marketing. The output of Step 1 is the VOC expressed in the form of a hierarchy tree and other well organized lists of the needs together with their associated priorities as understood and agreed to with the customers and stakeholders' representatives.

The most useful formats for the descriptions of the needs are scenarios, solutions to problems, or benefits to the entity with the need. This is because customers buy benefits and solutions, not features (King, 1989). These descriptions of the needs should be

- Positive statements whenever possible, expressed in qualitative terms, not necessarily in numbers. That conversion happens later.

- Expressed in the customer's language using definitions that are derived from information provided by the customers and are interpreted identically by all stakeholders (King, 1989). 
Step 1 also contains an activity which determines the priority of the needs. There are a number of techniques for the prioritization of a large number of needs. We initially tried using a technique known as Analytical Hierarchical Process (AHP) (Saaty, 1990), but found that while the method was helpful in performing the task, it was also a very time consuming one. An alternative approach known as Nominal Group Technique (NGT) (Jogger, 1985) was found to provide the same benefits while being much simpler and faster.

Step 2: Determination of the remaining requirements: This is the step that determines the remaining requirements (documented in the form of requirement requests ${ }^{2}$ ). These may come from standards, regulations, and any other source not participating in Step 1. For example, some requirement requests may be inherited from similar systems or from past experience. Applying an object-oriented database approach to storing requirements facilitates the inheritance of requirements, but does not necessarily assist in determining the relevance of requirements inherited from a similar system (Kasser, 2003). These requirement requests must be added to the VOC to complete the set of requirement requests.

Step 3: Creation of the New Product Definition: Step 3 the transformation phase, is the heart of NPD. It is where the communication between the representatives of the VOC and the representatives of the VOE takes place. This step is usually performed in a facilitated workshop in the form of a very intensive teamwork exercise in which the few most important target value decisions are agreed upon by all the participants in the process and reflect the mutual understanding of all the side interests and limitations.

Step 3 transforms the VOC produced in Step 1 and the other requirement requests identified in Step 2 into target values for the most critical requirements (the initial definition of the new product) and their impact on the manufacturing process. This transformation process, described from the information flow perspective, contains the following steps (Kasser, 2000):

- Prioritize each element of the VOC and external requirement (done in Step 1).

- Determine if a contradiction exists with other requirements.

- Determine coupling and dependencies (correlations) with other requirements and perform trade offs as needed.

- Perform an impact assessment using an Integrated Product and Process Team (IPPT). The impact assessment must:

- Estimate the cost/schedule to implement. (at this point it is a rough estimate)

- Determine the cost/schedule drivers - factors that are responsible for the greatest part of the cost/schedule.

- Perform a sensitivity analysis on the cost/schedule drivers.

- Determine if the cost drivers are really necessary and how much modification can be made by negotiating the requirement with customers based on the results of the sensitivity analysis.

- Make the decision to accept, accept with modifications, or reject.

- Notify the originator.

- Document the decision(s) in the requirement repository.

- If the requirement is accepted, allocate the implementation to a specific Build modifying the Work Breakdown Structure (WBS) appropriately.

\footnotetext{
${ }^{2}$ The term Requirement Request is used to differentiate between a signed of and approved text-mode requirement and a statement of need.
} 
Step 3 thus builds a modified House of Quality documenting the most important decisions leading to the initial PBS. Decisions about target values are made on the basis of a sensitivity analysis which may require the final target values to be negotiated with the customer. The sensitivity analysis may discuss not only the effect on performance but also on other attributes (main concerns of the production organization) such as the risk and difficulty of achieving the target values, the effect on cost, time to market or on conceptual considerations. The discussions in this step of the process may also have to consider some aspects of the design and implementation process. While the output of the stage are requirement requests stated in terms of "what has to be done to implement the requirement", rather than "how it is to be implemented", the design team must, in this step of the NPD meta-methodology, determine that there is at least one way of implementing the requirement to prove feasibility of implementation. After all, there is little point in drafting a requirement that cannot be met.

The initial decisions on the target values are followed by an impact assessment on the main concerns of the organization such as risk, difficulty of achieving the target values, the effect on cost, time to market and other conceptual considerations. Finally action items are assigned to the appropriate team members to verify achievement of the target values.

At this point the team can create the basis for the design quality measurement (DQM) system. The measurement system is based on Customer Satisfaction Rating (CSR) functions, linked to the target values (Hari, Weiss and Zonnenshain, 2001). A similar type of rating for tenders has been introduced by the US Defense Department as "utility graphs"(DOD).

Step 4: Production of a complete Performance Based Specification: Once Step 3 is complete, a small group of individuals completes the PBS document because most of the remaining requirements are derived from the decisions made in Step 3 or are obvious to the team working on Step 4. If necessary this group can communicate with the appropriate stakeholders to clarify any obscure points or revisit decisions.

Step 5: The Stage Gate Review: The NPD meta-methodology ends with a Stage Gate review such as that mandated in the PRINCE 2 methodology (Bentley, 1997). This is a formal Systems Requirements Review (SRR) with the participation of the senior decisionmakers such as top management and customers' senior representatives. The purpose of this review is

- To document consensus that the product when produced will meet the VOC.

- Verify that adequate resources have been appropriated to produce the product (Kasser, 1995).

Since all the information for this review has been decided and documented in the previous steps of the NPD meta-methodology, the SRR is very focused, well organised and takes only a few hours ${ }^{3}$.

\section{Lesson Learnt: QFD does not Support Making Target Value Decision and Implication Analysis for Complex Systems}

QFD often does not generate the necessary information needed to make the informed critical decisions required to produce specifications. It is not suited for performing a sensitivity analysis on the consequences of the decisions, it does not incorporate the ability to discuss affordability or "willingness to pay" issues with the customer and does not contain the provision to produce an action-plan and high level verification-plan.

\footnotetext{
${ }^{3}$ Depending on the scope of the project.
} 


\section{Remedy: The Target Values Decision Table}

The remedy for this lack of support developed during the last 15 years of using and modifying QFD, is to add a Target Value Decision Table (TVDT) that contains the quantitative or semi quantitative target values for the most important design characteristics, trade offs, dependencies and relevant performance of competing products to facilitate decisions that will position the new product relative to the competitors in the market as described below. The TVDT and the process of filling in its data have been considered by most of the team members as

1. the most important part of the process;

2. building the consensus, and

3. the most important modification to the traditional QFD process.

Figure 2 is an example of the TVDT for the relevant performance of a typical product namely a flashlight. The TVDT is shown on a screen throughout the decision making process of Step 3 and is populated by the team members. The product characteristics and their relative importance (Weighting) are transferred from the modified House of Quality according to the ranking order the most important one being at the top.

The discussion on each Product Characteristic starts with introduction by the senior VOE representative (usually the system engineer) of the characteristics, the range of debate and possible implications. Then trade offs against the more important (previous) decisions are raised, and only the identification number or the name of the conflicting characteristics are noted in the trade off column. The idea behind this is that in case of a conflict between two characteristics, the customer will prefer better performance in the more important characteristics compromising on the less important ones and aiming at the best value that can be achieved.

\begin{tabular}{|c|c|c|c|c|c|c|c|c|c|c|c|c|c|}
\hline & \multicolumn{3}{|c|}{$\begin{array}{l}\text { Project: } \\
\text { Flashlight for the Elderly }\end{array}$} & \multicolumn{6}{|c|}{$\begin{array}{l}\text { Company: } \\
\text { |Light Light }\end{array}$} & \multicolumn{4}{|c|}{$\begin{array}{c}\text { Workshop Date: } \\
\mathbf{1 . 1 . 0 2} \\
\end{array}$} \\
\hline \multicolumn{14}{|c|}{ Decisions Table } \\
\hline & $\begin{array}{l}\text { Product } \\
\text { Characteristics }\end{array}$ & & $\begin{array}{l}\text { Trade } \\
\text { - offs } \\
\end{array}$ & Ref & Proc & ucts & $\begin{array}{l}\text { Target } \\
\text { Values }\end{array}$ & $\operatorname{lmp}$ & lic & ation & & & \\
\hline No. & Units / LIST & W & Charact. & Now & $x$ & $\mathbf{Y}$ & Ver. 1 & Diff & $\$$ & TTM & Conceptual & $\mathrm{Al}$ & Remarks \\
\hline \begin{tabular}{|l|}
1 \\
\end{tabular} & Total Volume (cc) & $16 \%$ & & 220 & 80 & 75 & 40 & $\mathrm{O}$ & 0 & $\Delta$ & & 1 & \\
\hline \begin{tabular}{|l|}
2 \\
\end{tabular} & Total Weight (grams) & $16 \%$ & 1 (vol) & 220 & 75 & 70 & 60 & $\mathrm{O}$ & 0 & $\Delta$ & & 1 & \\
\hline 3 & $\begin{array}{l}\text { Continuous } \\
\text { Operation Time ( } \mathrm{min})\end{array}$ & $13 \%$ & $\begin{array}{l}1 \text { (vol), } \\
2 \text { (wgt) }\end{array}$ & 40 & 20 & 20 & 20 & $\bullet$ & 0 & $\mathrm{O}$ & $\begin{array}{c}\text { New bulb or battery } \\
\text { concept }\end{array}$ & 23 & \\
\hline 4 & $\begin{array}{l}\text { Time to Locate and } \\
\text { Operate (sec) } \\
\end{array}$ & $12 \%$ & $\begin{array}{l}1 \text { (vol), } \\
2 \text { (wgt) }\end{array}$ & 10 & 14 & 12 & 8 & $\mathrm{O}$ & $\Delta$ & $\Delta$ & $\begin{array}{c}\text { W/O additional volume } \\
\text { (key holder ?) }\end{array}$ & 4 & \\
\hline 5 & Product Mfg Cost (\$) & $12 \%$ & $1,2,3,4$ & $3 \$$ & $2 \$$ & $1.6 \$$ & 1.3 & 0 & & 0 & & 5 & \\
\hline 6 & $\begin{array}{l}\text { Design Level (scale } \\
1-5)\end{array}$ & $10 \%$ & 4,5 & 3 & 3 & 2 & 4 & $\mathrm{O}$ & 0 & & & 6 & \\
\hline 7 & Operations to Failure & $10 \%$ & 5 & 500 & 400 & 500 & 500 & $\Delta$ & $\Delta$ & $\Delta$ & & 7 & \\
\hline \begin{tabular}{|l|}
8 \\
\end{tabular} & Light Intensity (Lux) & $6 \%$ & $1,2,3,6$ & 300 & 300 & 400 & 200 & $\Delta$ & $\Delta$ & $\Delta$ & & 8 & \\
\hline 9 & \begin{tabular}{|l|}
$\begin{array}{l}\text { Automation Level } \\
\text { (List 1) }\end{array}$ \\
\end{tabular} & $4 \%$ & $3,4,5,6$ & 2 & 2 & 2 & 1 & $\Delta$ & $\Delta$ & $\Delta$ & & 9 & \\
\hline 10 & $\begin{array}{l}\text { Time to change } \\
\text { batteries (sec) }\end{array}$ & $1 \%$ & 5 & 25 & 30 & 60 & 25 & $\Delta$ & $\Delta$ & $\Delta$ & Disposable & 10 & \\
\hline
\end{tabular}

Figure 2 Example of Decision Table for the flashlight case study

Then the second (technical) benchmark takes place. The relevant information about the reference products for the decision on each target value is presented here. The best in class is emphasized. Then a short discussion on where this product should be aimed is conducted. 
Production of the Target Value column is the formal goal of the entire NPD process. It is where a consensus between the VOC and the VOE should be achieved. This decision sometimes requires deep discussions, bringing into consideration all the information that has been shared and learnt up to this point. Usually this decision is based on the contribution from the various experts who should be represented in the room. Sometimes this column is split into more than one column in instances such as where decisions are being made on the characteristics of several versions or releases of the new product.

Implication Analyses: After the decision on the target values a discussion on the implication of the target values decisions takes place. These implications are documented in the decision table (see Figure 2). The team tailors the implications columns according to their concerns. Some implications are frequently analyzed such as the technical difficulty of achieving the target value, the effect on cost and time to market and the implication on the concept selection. The team use symbols to present the implication as follows:

- Critical implication, example: the decision on this target value is the prime cost driver of the system cost.

O - Important implication, example: the decision on this target value has a significant effect on the time to market but it is not the prime system time to market factor

$\Delta$ - Minor implication, example: the decision on this target value involves a minor risk since the same target value has been achieved in a similar system.

One of the issues affecting the target values is the worth of the feature to the customer, namely determining how much money the customer is willing to pay for it.

Willingness to Pay (WTP): WTP articulates the flexibility of the cost to the customer (Smith and Nagle, 2002) by defining the readiness of customers to pay additional costs for some benefit. The determination of the WTP of the customer allows the product developers to satisfy the customers' needs according to the customer willingness to pay for them (needs satisfied completely, partially or not al all). In NPD we use the following three levels of WIP:

- Essential: This level of need is the reason why the customer will buy the product. He relates most of the cost to this need and is ready to pay for it. An example of essential need is the ability of a car to transfer the customer quickly from one location to another. The customers will agree to pay some tens of thousands of dollars for this benefit.

- Beneficial: The customer needs it but is not willing to pay for meeting the need ${ }^{4}$. The amount of money he would like to pay it is less than the amount of money the supplier demands. If the customer cannot pay the total cost of a beneficial need he will have to discuss with the supplier what partial benefits he can get for the amount he would like to spend. An example of beneficial need is the desire of the customer to control the temperature inside his car. He would accept paying a few hundred dollars but would not be willing to pay a thousand dollars.

- Luxury: Satisfaction of this need will satisfy or even delight the customer but he will not agree to pay anything for it, or he will only agree to pay some insignificant amount of money. An example of a luxury need is an automatic lowering the volume of the car audio system when a cell-phone call comes in. It is nice to have such a feature in the car but the customer would not agree to pay more than few dozens of dollars for it or will even expect to get it free of charge.

The essential needs are obviously the most important needs (high priority) while the luxury needs are of low priority and will be satisfied only up to the extent of the WTP for

\footnotetext{
${ }^{4}$ He may not have the budget.
} 
them.

Action Plan: The target value decision table (see Figure 2) includes:

1. tasks required for completion of the decision table,

2. tasks to be performed after completion of the workshop and before completion of the specification document,

3. tasks scheduled for discussion during the SRR or even

4. tasks for the system engineer to analyze or to monitor during later design stages.

\section{Lesson Learnt: The Methodology for Definition of a Complex System Must be Tailored to the Unique Characteristics of Each Product, Organization and Culture.}

NPD is a Meta-methodology for achieving a complete set of verified and validated requirements. It can be implemented using any appropriate methodology, process or tool that does the job. However, these methodologies and processes will need to be tailored, namely customised or combined with other methodologies and processes.

\section{Remedy: Architecture of New Product Definition Process}

The remedy is that one must choose specific tools and practices for executing the project. Knowledge of the capability of tools and techniques is only part of the knowledge required to apply them successfully. The knowledge needed to tailor them to the unique needs of each situation is essential but unfortunately to date this knowledge is rarely taught in courses and documented in the literature. Designing an appropriate mixture of methodologies for use in any specific organisational situation is a job that needs the specialised skills of a Process Architect (Kasser, 2005) who understands the methodologies, the organisation and the domain of the product.

There are a number of soft system methodologies for the market research and customer inquiry processes that take place in Step1 to capture the customers' needs. These include scenario building, user/customer interviews, questionnaires, customer visits, observation, customer value analysis, development of Use Cases (and other UML techniques), contextual inquiry, focus groups, hierarchical customer needs tree, Willingness to Pay (WIP) analysis, and the Nominal Group Technique (NGT).

Appropriate methodologies have been discussed in (Avison and Fitzgerald, 2003) (Checkland, 1993) (Flood and Jackson, 1991). NPD must also be tailored for the type of system being developed. (Shenhar and Bonen, 1997) present a two-dimensional taxonomy in which systems are classified according to four levels of technological uncertainty, and three levels of system scope. They then describe the differences found in systems engineering styles in various areas, such as system requirements, functional allocation, systems design, project organization, and management style. They also claim that adapting the wrong system and management style may cause major difficulties during the process of system creation. As a guide to tailoring the methodology, (Shenhar and Bonen, 1997) suggests the following distinction:

- Type A-Low-Tech Projects: Type A projects are those projects that rely on existing and well-established technologies to which all industry players have equal access. The system requirements of Low-Tech Projects are usually set by the customer prior to signing the contract and before the formal initiation of the project execution phase.

- Type B-Medium-Tech Projects: Type B projects rest mainly on existing technologies; however, such systems incorporate a new technology or a new feature 
of limited scale. Their requirements are mainly set in advance; however, some changes may be introduced during the product development phase. This process often involves a joint effort of the contractor and customer. It may also require the involvement of potential customers in the process.

- Type C-High-Tech Projects: Type $\mathrm{C}$ projects are defined as projects in which most of the technologies employed are new, but existent-having been developed prior to the project's initiation. System requirements are derived interactively with a strong involvement of customers or potential users, and many changes are introduced.

- Type D-Super-High-Tech Projects: Type D projects are based primarily on new, not entirely existent, technologies. Some of these technologies are emerging; others are even unknown at the time of the project's initiation. System requirements are hard to determine; they undergo enormous changes and involve extensive interaction with the customer.

In Step 2, in many instances the requirements specifications document detailed functional requirements but tend to underestimate or completely ignore the non-functional requirements such as Human-System interface requirements. Documented processes that help gather these requirements (as requirement requests until accepted in Step 5) include:

- AMMETH, a proposed seven steps methodology (Guida and Lamoerti, 2000) which addresses the important issue of identifying the requirements for advanced humansystem interface in the context of a disciplined requirements engineering process and, helps carry out the requirements analysis of human-system interfaces in a disciplined and effective way.

- A process to elicit nonfunctional requirements and show how to integrate them into the class, sequence, and collaboration diagrams of UML and how Use Cases and scenarios can be adapted to deal with Nonfunctional requirements (Cysneiros and Leite, 2004).

- Checklists for identifying these requirements such as (DSMC, 1996).

As a further example, (Kasser and Mirchandani, 2005) describe a case study of a situation in which a soft-systems methodology coupled with an object-oriented approach for viewing the requirements was used in a plurality environment to gather a set of requirements. By considering the cost, priority, and risk attributes of the requirements, as well as clarifying the wording of the requirements for verifiability, an optimal product architecture and development process was achieved in a relatively short period of time compared with the standard systems engineering process. Moreover, the PBS presented at the SRR for the product was deemed complete and comprehensive by the customer. In this instance, Steps 1 and 2 were performed in parallel, and Step 3 was performed by visiting the stakeholders in turn and going through the process of requirements negotiation and analysis without formally using QFD, the performance requirements were agreed to by all the stakeholders, the only area of requirements needing negotiation being the installation (supply chain) requirements.

\section{Lesson Learnt: QFD Cannot be Used When Requirements are Stated in Tender Documents}

Some customers prefer to use, tender documents or detailed requests for proposal (RFP) to list their requirements. In the event this situation cannot be avoided, the new-product definition team needs a way to determine the real needs of the customers. 


\section{Remedy: Perform Requirements Analysis}

The NPD implementation of Requirements Analysis is based on the spreadsheet implementation of the Requirement Analysis Form shown in Figure 3. It necessitates going through the requirements document with the customers or with the representatives of the VOC and analyzing each requirement using the Requirement Analysis Form in order to determine the customers' real need. Good question to ask the customer in this dialog are "why do you want this requirement?" and "how will you know when the requirement is met?"

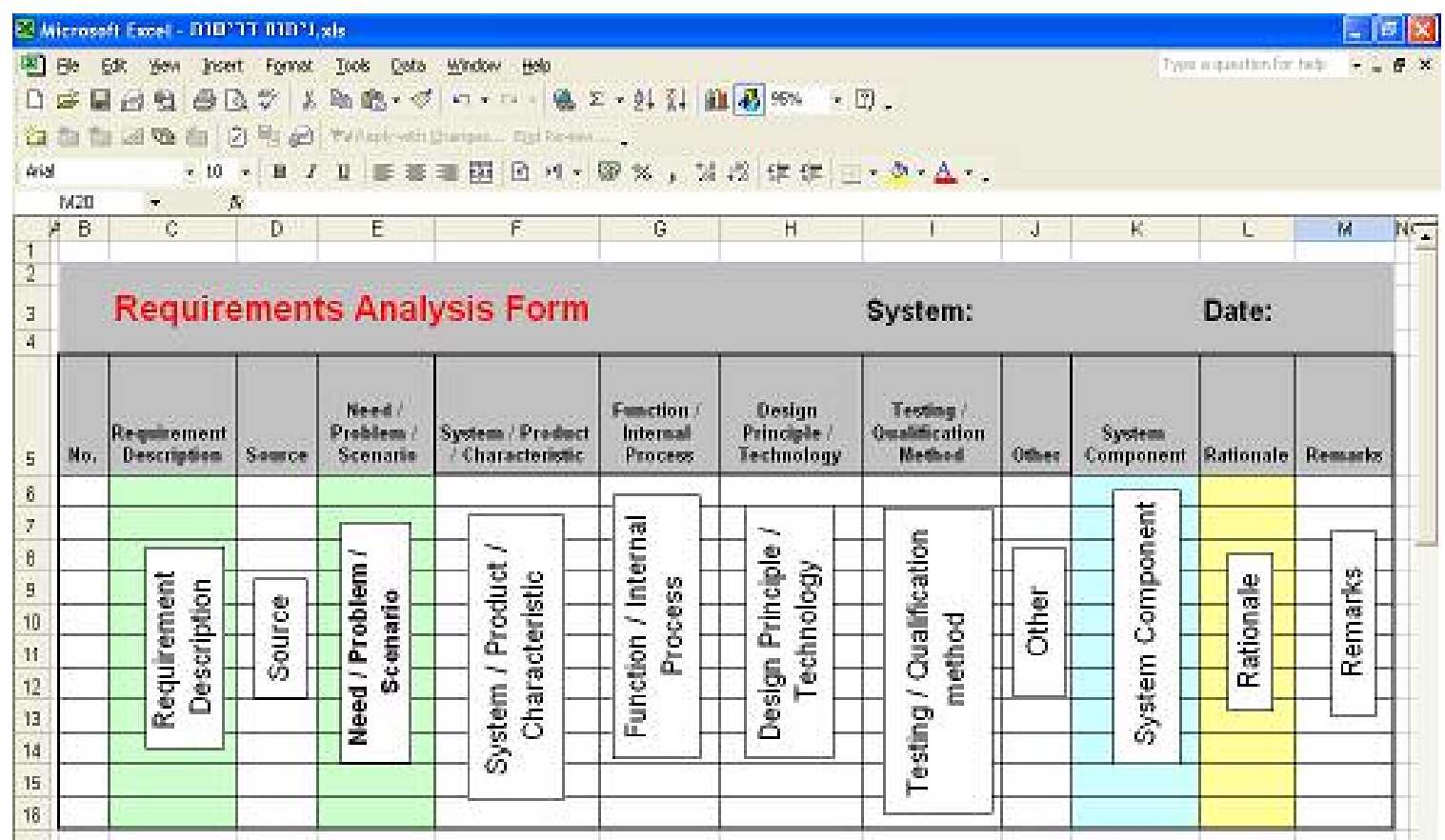

Figure 3 Requirement Analysis Form

Requirements Analysis is an activity performed to determine the VOC in Step 1 of NPD, It comprises the following steps:

1. Copy the original identification number and requirement text from the requirements document to the Number and Requirement Description columns in the form.

2. Identify and document the Source of this requirement

3. Analyze and categorize the nature of the requirement and enter them in the appropriate column. Possible categories are:

- Need/Problem/scenario

- System/product characteristic

- Function/Internal Process

- Design Principle/Technology

- Testing/ Qualification Method

- System Component.

- Other

4. Discuss the rationale for each requirement and enter it in the Rationale column.

5. If the requirement is other than a Need/Problem/Scenario, discuss the need behind the requirement with the customer representative. Once the reason behind the requirement request is found (real need), the information is documented in the appropriate column in the Requirements Analysis form. 


\section{Conclusions}

More than 15 years of the application of well-known methods has led to NPD which:

- Is based on lessons learnt from success and failure cases studies, improvements and modifications

- Has been validated via many workshops.

- brings to the systems engineering process a tried and tested approach for converting customer's needs to performance based requirements and other attributes of the requirement in the product and process domains that allows the product to be produced more rapidly and correctly than is typically done using other methodologies for developing new products.

\section{References}

Avison, D. and Fitzgerald, G., Information Systems Development: Methodologies, Techniques and Tools, McGraw-Hill Education (UK), 2003.

Bentley, C., PRINCE 2 A Practical Handbook, Butterworth Heinemann, 1997.

Checkland, P., Systems Thinking, Systems Practice, John Wiley \& Sons, 1993.

Cohen, L., Quality Function Deployment: How to Make QFD Work for You, Pearson Professional Education, 1995.

Cysneiros, L. M. and Leite, J. C. S., "Nonfunctional requirements: from elicitation to conceptual models", IEEE Transactions on Software Engineering Volume 30 No. 5, pages $328-350,2004$.

DOD, DOD Performance Assessment Guide Module 2, http://www.dtic.mil/performance/pamanua2.html.

DSMC, Systems Engineering Management Guide, vol. May 1996, Defence Systems Management College, 1996.

Flood, R. L. and Jackson, M. C., Creative Problem Solving, Wiley, 1991.

Guida, G. and Lamoerti, G., "AMMETH: A Methodology for Requirements Analysis of Advanced Human - system interface", IEEE Transactions on Systems, Man, and Cybernetics - Part A: Systems and Humans Volume 30 No 3, pages 298 - 321, 2000.

Hari, A., Weiss, M. P. and Zonnenshain, A., "Design Quality Metrics Used as a Quantitative Tool for the Conceptual Design of a New Product", ICED 01, 2001.

Hari, A. and Zonnenshain, A., "Quality Function Deployment (QFD) In Complex Systems", the National Conference of the Israel Society of Quality, 1993.

Jogger, M., "Memory Jogger," GOAL/QPC, Mathuen, MA, 1985.

Kasser, J. E., Applying Total Quality Management to Systems Engineering, Artech House, Boston, 1995.

Kasser, J. E., "A Framework for Requirements Engineering in a Digital Integrated Environment (FREDIE)", Proceedings of the Systems Engineering, Test and Evaluation Conference, 2000.

Kasser, J. E., "Object-Oriented Requirements Engineering and Management", The Systems Engineering Test and Evaluation (SETE) Conference, 2003.

Kasser, J. E., "Introducing the Role of Process Architecting", The 15th International Symposium of the International Council on Systems Engineering (INCOSE), 2005.

Kasser, J. E. and Mirchandani, C. J., "The MSOCC Data Switch Replacement: A Case Study in Elicitating and Elucidating Requirements", The 15th International Symposium of the International Council on Systems Engineering (INCOSE), 2005.

King, B., Better Designs in Half the Time, Goal /QPC, Methuen MA, 1989.

Saaty, T., Decision Making for Leaders, RWS Publications, 1990.

Shenhar, A. J. and Bonen, Z., "The New Taxonomy of Systems: Toward an Adaptive Systems 
Engineering Framework", IEEE Transactions on Systems, Man, and Cybernetics Part A: Systems and Humans Volume 27, No. 2, March 1997, pages 137 - 145, 1997. Smith, G. E. and Nagle, T. T., "How Much Are Customers Willing to Pay?" Marketing Research Winter 2002, pages 20-25, 2002.

\section{Authors Biographies}

Dr. Amihud Hari is a facilitator, consultant and instructor of Engineering Design and Quality Methods. His experience includes many applications of Engineering Design Methodologies. He also teaches Engineering Design at the TECHNION, Haifa, Israel and is an Adjunct Professor at the System Engineering and Evaluation Centre (SEEC) in the University of South Australia. Dr Hari has published more than 40 papers on Engineering Design and quality methods and he is a co-editor of the Quality Language Book. He holds a B.Sc. in Industrial Engineering, M.Sc and Ph.D. in Quality Assurance and Reliability, from the TECHNION Haifa.

Prof. Joseph Kasser has been a practising systems engineer for 35 years. He is the author of "Applying Total Quality Management to Systems Engineering". He holds a Doctor of Science in Engineering Management from The George Washington University, and is a Certified Manager. He is the DSTO Associate Research Professor at the Systems Engineering and Evaluation Centre at the University of South Australia. He performs research into the nature of systems engineering and the properties of object-oriented requirements. He is a recipient of NASA's Manned Space Flight Awareness Award for quality and technical excellence for performing and directing systems engineering.

Prof. Menachem P. Weiss graduated as ME at the TECHNION, Israel Institute of Technology, where he was later awarded the D.Sc. title. Prof. Weiss worked as Designer, Project Engineer and Head of a major R\&D department in RAFAEL, the Israeli missiles house for more than 25 years. Served as the Director of Procurement and member of the Top Management. In 1975 was awarded the National Defense Award, by the President of Israel. Since 1994 with the ME Faculty in the TECHNION, where he contributed to research and teaching in Design Theory and Methodology and in the development of practical Fatigue Models. 